\title{
PERASAAN POSITIF PADA KORBAN BENCANA ALAM DI LOMBOK, SULAWESI DAN BANTEN
}

\section{POSITIVE FEELING ON NATURAL DISASTER VICTIMS IN LOMBOK, SULAWESI AND BANTEN}

\author{
${ }^{1)}$ Nurfadhilah \\ ${ }^{1)}$ Program Studi Kesehatan masyarakat, Universitas Muhammadiyah Jakarta. \\ Jalan KH Ahmad Dahlan, Cireundeu, Tangerang Selatan, 16519 \\ Email : nurfadhilah.nf@umj.ac.id
}

\begin{abstract}
ABSTRAK
Indonesia merupakan negara yang berisiko sangat tinggi mengalami bencana alam. Bencana tersebut berdampak besar bagi kehidupan manusia dan pembangunan bangsa. Pengabdian ini bertujuan untuk melihat gambaran tentang perasan positif korban terdampak pasca rangkaian bencana alam di Lombok, Sulawesi, dan Banten pada tahun 2018-2019. Metode yang dilakukan yaitu kombinasi edukasi dengan teknik curah pendapat, bercerita, dan diskusi. Peserta yang dilibatkan adalah pengungsi korban dan penyintas gempa kelompok usia kanak-kanak, dewasa, dan lansia baik laki-laki maupun perempuan serta relawan independen dan institusi pemerintah serta swasta. Kegiatan dilaksanakan pada Agustus 2018 hingga Januari 2019. Temuan menunjukkan bahwa umumnya pengungsi memiliki perasaan negatif akibat trauma maupun karakteristik pribadi (kepribadian) dan bisa jadi situasi budaya. Namun, ada di antara mereka yang kondisi mentalnya sukup stabil dan positif. Perasaan positif harus ditularkan kepada korban dan penyintas lain agar mereka mampu menemukenali potensi yang masih dimiliki. Diperlukan intervensi sistematis untuk mengembangkan masyarakat agar segera bergerak, membangun, dan memberikan kontribusi terbaik bagi upaya pemberdayaan.
\end{abstract}

Kata Kunci : bencana alam, korban, perasaan positif.

\begin{abstract}
Indonesia reognised as a high potential of natural disaster country. The impact of the disasters is very significant to human life and national development. The purpose of this study to reveal positive feeling among the victims of Lombok, Sulawesi, and banten natural disasters series. The methode conducted by using education combined with brainstorming, story telling, and disscussion. The paticipants were refugees and survivors of various age (children, youth, and elderly) both male and female as well as independent and government volunteers. The study was conducted from August 2018 untul January 2019. Generally the refugees showed negative feelings due to trauma and individual characteristic (personality) and possibly cultural situation. Hence, there were a little amount of them having stabil and positive mental condition. These positive feelings need to be spread out in order that the other survivors together could identify potentials they still had. Systematic intervention are needed to develop the community and make them move, build, and contribute the best to empower themselves.
\end{abstract}

Keyword: positive feeling, refugee, natural disaster 
AS-SYIFA: Jurnal Pengabdian dan Pemberdayaan Kesehatan Masyarakat

\section{PENDAHULUAN}

Secara geologis Indonesia terletak di antara 3 lempeng tektonik (Eurasia, Pasifik, dan Hindia-Australia) sehingga rentan terhadap gempa bumi, tsunami, letusan gunung api, dan bencana geologis lain. Pertengahan hingga akhir tahun 2018 lalu terjadi rangkaian gempa, tsunami, dan likuifaksi hebat di wilayah Lombok, Sulawesi, dan Banten. Dampaknya luar biasa, bahkan hingga kini masih ada kondisi yang belum sepenuhnya pulih. Secara global, bencana mengakibatkan kerugian ekonomi paling banyak pada negara maju; namun jumlah korban jiwa jauh lebih tinggi pada negara-negara berkembang. Lebih dari 95\% korban jiwa bencana alam yang terjadi sejak 1970 hingga 2008 terdapat di negara berkembang. Sepanjang 2015-2016, gempa bumi tercatat 34 kejadian, korban luka dan meninggal mencapai 1.085 orang (BPS Indonesia, 2017).

Kurangnya perhatian pada penanganan korban bencana alam, khususnya upaya pemulihan trauma di setiap bencana alam yang terjadi di Indonesia merupakan masalah yang belum ditangani secara serius dan efektif. Padahal trauma dapat menyebabkan masalah besar dalam kehidupan pasca bencana alam. Bencana berarti juga terhambatnya laju pembangunan. Berbagai hasil pembangunan ikut menjadi korban sehingga perlu adanya proses membangun ulang. Siswa pun harus terpaksa berhenti sekolah. Kenyataan seperti ini berarti pula muncul kemungkinan kegagalan di masa mendatang (World Bank, 2016).

Situasi sebaliknya terjadi pada orang yang memiliki perasaan negatif seperti marah, tertekan, ditolak, pedih/sakit/tersiksa, dan semacamnya. Perasaan semacam ini memicu tindakan kekerasan, dan kekuatan emosional juga meningkatkan kekuatan fisik. Jadi, dampak yang dirasakan lebih kuat dan bersifat merusak (Bandura, 2016). Seseorang akan bertindak sesuai situasi, dan situasi sendiri adalah persepsinya terhadap lingkungan (Karen Glanz, Barbara K. Rimer, 2017). Lingkungan yang eksis dapat dipersepsi berbeda oleh orang dengan tingkat kognitif dan emosi berbeda, akhirnya tindakan yang diambil tentu berbeda pula. Situasi bencana memungkinkan kondisi yang ada dipersepsi secara negatif.

Perlu diupayakan kegiatan pemulihan dan upaya pengembangan mental korban agar tidak berlarut-larut dalam kesedihan dan meninggalkan kegiatan yang produktif dalam upaya mempertahankan dan meningkatkan kesehatan fisik dan mentalnya. Kegiatan bertujuan untuk mendapatkan gambaran tentang perasan positif korban terdampak gempa. Manfaat kegiatan pengabdian masyarakat yang diharapkan yaitu ditemukannya perasaan positif korban dan penyintas bencana alam untuk kemudian ditularkan kepada sebanyak-banyaknya orang di lingkungan sekitar. Perasaan positif bahkan dapat dikembangkan pada orang yang memiliki kecenderungan untuk melakukan bunuh diri (Van Bentum et al., 2017). Selanjutnya diharapkan masyarakat dapat menemukan potensi yang masih dimiliki dan menggunakannya untuk pemberdayaan sehingga perlahan akan terbangun kembali masyarakat yang mandiri, tidak terus bergantung pada orang/institusi lain.

\section{METODE}

Pengabdian ini dilakukan dengan menggunakan strategi kombinasi edukasi. Teknik yang digunakan yaitu curah pendapat, bercerita, dan berdiskusi. Lokasi pengabdian antara lain:

a. Tiga titik posko pengungsi di Kabupaten Lombok Utara

b. Dua titik posko pengungsi di Kabupaten Lombok Timur

c. Satu titik posko relawan di Kota Mataram

d. Dua titik posko pengungsi di Kota Palu

e. Dua titik posko pengungsi di Kabupaten Sigi

f. Satu titik posko pengungsi di Kabupaten Donggala

g. Dua titik posko pengungsi di Kabupaten Pandeglang 
Pengumpulan data dilakukan pada Agustus 2018 hingga Januari 2019. Informan kunci antara lain pengungsi korban gempa kelompok usia kanak-kanak, dewasa, dan lansia baik laki-laki maupun perempuan serta relawan independen dan institusi pemerintah serta swasta. Jumlah informan sebanyak 25 orang yang diwawancara dan peserta curah pendapat 35 orang di 2 titik pengungsi serta 5 orang di kalangan relawan.

\section{Tahapan Pengabdian}

1. Menentukan Lokasi Kunjungan

Malam sebelum dilakukan kunjungan diadakan pertemuan koordinasi dan persiapan kunjungan dihadiri tim penanganan trauma dan pengobatan/pemeriksaan kesehatan. Tim yang terlibat yaitu Relawan Indonesia Mandiri dan Yayasan Pundi Amal SCTV untuk lokasi Lombok, Teknisi Indonesia Bergerak (TIGER) dan Delegasi Kemanusiaan Peduli Indonesia (DEKAP) untuk lokasi Sulawesi, dan Yayasan Peduli Yatim dan Dhuafa (PYD) untuk lokasi Banten.

2. Pelaksanaan Intervensi

Intervensi dilakukan dengan membuka pos pelayanan kesehatan serta penanganan trauma bagi dewasa dan kanak-kanak. Bentuk kegiatan intervensi bagi kanak-kanak berupa mendongeng dilanjutkan dengan sesi diskusi dan curah pendapat bagi khalayak dewasa.

Sebelum kegiatan fasilitator mempersiapkan gambar kue/makanan yang dibagi menjadi dua tidak sama besar. Ada kalanya tidak tersedia bahan untuk membuat gambar kue, maka dapat memanfaatkan potongan kertas dan gunting atau menggunakan papan (whiteboard) dan spidol untuk menggambar.

Fasilitator memperkenalkan diri dan menjelaskan tujuan kegiatan, dilanjutkan dengan melakukan identifikasi informan (nama dan umur). Setelah terbangun hubungan baik dengan pencairan suasana, fasilitator mengajukan beberapa pertanyaan:

"Bagaimana perasaan Bapak/Ibu saat ini?"

Setelah beberapa peserta maju dan menjawab pertanyaan (upayakan hingga ada yang menggambarkan perasaan positif), fasilitator bercerita tentang Kue dan Dua Anak.

"Bapak/Ibu, punya kue/makanan favorit?"

"Silakan tutup mata dan bayangkan ada sepiring besar kue/makanan itu.. boleh dicoba sedikit... enak ya?"

"Sekarang boleh buka matanya. Ternyata kue itu bukan untuk dimakan sendiri tapi akan diberikan kepada ada 2 anak. Namanya A dan B, jadi kuenya kita bagi ya... seperti ini...

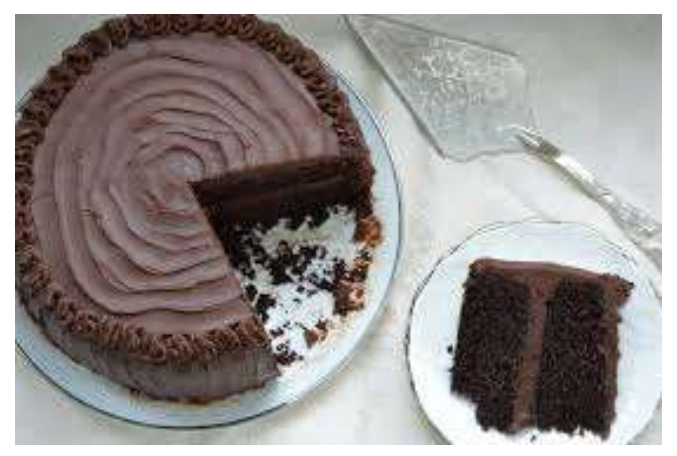

Anak A dapat bagian yang atas

Anak B dapat bagian yang bawah

Kira-kira wajah A senyum atau cemberut?

Kalau wajah B?"

Lanjutkan dengan curah pendapat.

Gambar 1. Potongan kue tidak sama besar 


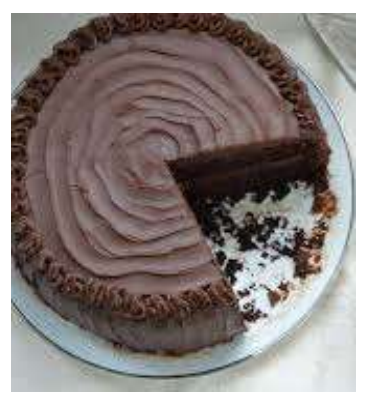

Berikutnya, "Kemudian kita tanya kepada A, mengapa wajahnya demikian. Lalu ia menjawab, "Mengapa ada yang hilang/tidak sempurna?"

Gambar 2. Potongan kue untuk anak A

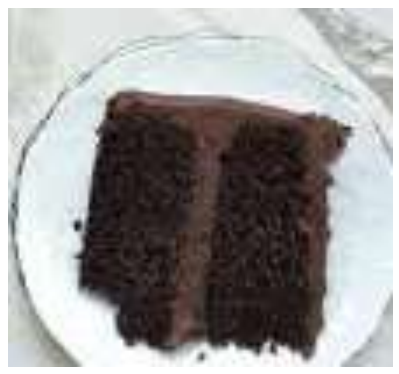

Sedangkan B ketika ditanya hal yang sama menjawab, "Terima kasih, Saya diberi kue, Saya mau makan bersama seseorang yang Saya sayangi"

Gambar 3. Potongan kue untuk anak B

Bagaimana menurut Bapak/Ibu tentang A dan B?"

Lanjutkan hingga selesai curah pendapat dan peserta dapat menyimpulkan kisah tersebut serta mengambil pesan untuk mereka terapkan bagi diri sendiri.

Pesan penting dalam kisah ini yaitu ada dua jenis manusia, yang selalu memiliki perasaan negatif (sedih, marah, kecewa, dan sejenisnya) dan yang selalu memelihara diri untuk memiliki perasaan positif (senang berbagi, ceria, bersyukur, dan sejenisnya). Jika kita memiliki perasaan positif, kita dapat selalu melihat kebaikan diri sendiri dan orang lain, kita bisa arahkan fokus pada solusi, bukan masalah. Jadi, dengan berkolaborasi, kita akan bangkit berjuang dan tidak perlu bergantung pada orang lain lagi.

\section{HASIL DAN PEMBAHASAN}

\section{Bencana alam dan Lingkungan fisik}

Gempa berkekuatan 6.4 SR melanda lombok pada 29 Juli 2018. BMKG kemudian mengeluarkan pernyataan "Tidak akan muncul lagi gempa berkekuatan lebih besar daripada 6.4 SR. Akan ada gempa susulan dengan skala lebih kecil, hingga akhirnya mereda." Namun ternyata 5 Agustus gempa 7 SR kembali melanda Lombok. Korban meninggal 400 orang lebih dengan jumlah rumah rusak 61 ribu lebih. Tanggal 9 Agustus 2018, Lombok kembali diguncang gempa besar dengan magnitudo 6.2 SR. Masih dilanjutkan 19 Agustus Lombok dilanda 3 kali gempa besar. Gempa pertama 5.4 SR, gempa kedua 6.5 SR, lalu malamnya 7 SR kembali. Ketika gempa 7 SR tanggal 19 Agustus 2018 itu terlihat banyak orang pasrah. Karakteristik malam itu sama dengan malam tanggal 5 Agustus 2018. Listrik padam, gempa besar, lalu disusul gempa kecil-kecil setiap hampir 1 jam.

Beberapa masalah yang muncul saat dan pasca gempa di antaranya kehancuran fisik (bangunan dan organisme termasuk manusia) serta trauma dan tekanan psikologis. Masalah ini sangat berdampak pada situasi kesehatan masyarakat setempat. Sekitar 3.000 rumah rusak akibat bencana gempa di Kabupaten Lombok Utara. Kecamatan yang dianggap terkena dampak paling parah, yakni Kecamatan Pemenang dan Kecamatan Tanjung. Fasilitas yang 
menjadi sangat vital misalnya MCK (mandi, cuci, kakus) dan tempat sampah segera dibangun. Namun gempa susulan yang masih sering terjadi serta angin badai mengakibatkan terhambatnya pembangunan fasilitas fisik darurat, ditambah terputusnya akses karena longsor di banyak lokasi.

Bantuan logistik ada, namun tidak terdistribusi ke semua titik penampungan pengungsi. Jika ingin mencari barang yang dibutuhkan, sangat sulit ditemukan karena sistem pengiriman dan penerimaan belum cukup baik.

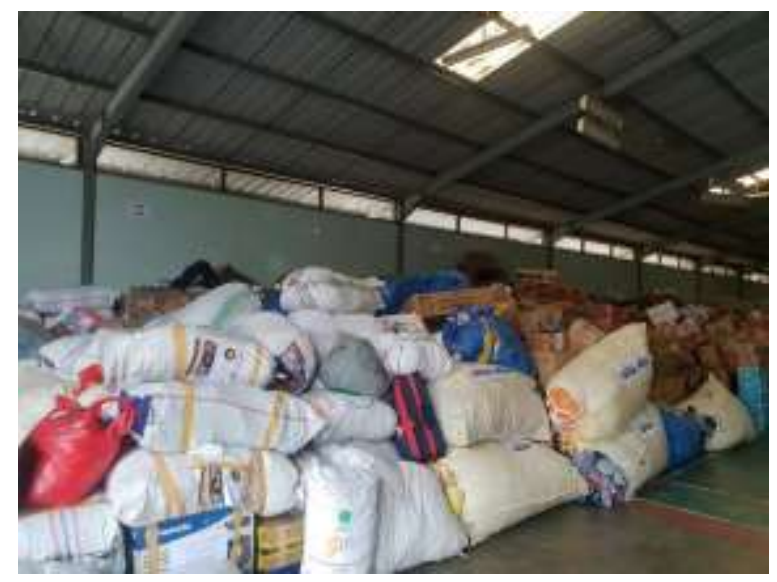

Gambar 4. Tumpukan barang di Gudang pangkalan Udara TNI AU Rembiga Sumber: WAG RIM

Situasi serupa juga terjadi di Sulawesi (likuifaksi dan tsunami) dan Banten (tsunami), bahkan dengan kejadian yang tanpa diduga serta dampak yang lebih dahsyat. Kesiapan masyarakat dan pemerintah relatif rendah.

\section{Bencana Alam dan Kondisi psikologis}

Tidak saja menyebabkan timbulnya korban jiwa ataupun menimbulkan kerusakan rumah dan infrastruktur, tetapi juga meninggalkan trauma yang luar biasa, terutama bagi kanak-kanak. Kejadian luar biasa yang dialami seseorang dan tidak mampu diantisipasinya seperti bencana alam dapat menyebabkan terganggunya kejiwaan orang tersebut. Keadaan ini diperparah dengan jumlah pengungsi yang tidak sesuai dengan tempat pengungsian. Mereka kebanyakan tidak mendapatkan tempat yang layak untuk tinggal bahkan hanya untuk beristirahat saja. Kurangnya pasokan makanan yang bergizi juga menyebabkan para pengungsi mudah terserang penyakit. Mereka tidak mampu bersekolah dan harus tidur di tempat yang seadanya. Kondisi ini dapat menyebabkan terjadinya penurunan kualitas mental sebagai dampak traumatis kejadian tersebut (Nugroho et al., 2013).

Membuang sugesti dan perasaan takut, lalu mengisi dengan sugesti positif dan lebih bermakna adalah konsep utama keberhasilan terapi traumatis (Vázquez et al., 2005). Selanjutnya, kita bisa mengupayakan pencarian perasaan positif dan mengembangkannya serta menyebarkan kepada komunitas. Salah satu informan misalnya, langsung bereaksi dengan kata trauma dengan menginterupsi, "Saya tidak trauma, kami tidak trauma." Beliau bahkan berupaya membangun dan menyadarkan masyarakat saat berkesempatan menjadi imam dan khatib shalat Jum'at, namun memang situasi masyarakat sangat emosional sehingga banyak yang bertangisan saat itu.

Pasca gempa mengguncang El Salvador pada Januari 2001, sebanyak 115 korban selamat diwawancara di pengungsian tentang kognisi positif dan emosi yang dialami selama tinggal di pengungsian. Mereka mengungkapkan pola reaksi dan emosi positif yang konsisten 
yang sangat potensial memberikan implikasi sebagai pelindung efek traumatis (Vázquez et al., 2005).

Penelitian pada petugas pemadam kebakaran menggambarkan reaksi positif lebih banyak ditandai dalam kuesionernya dibanding reaksi negatif (Moran \& Colless, 1995). Situasi yang terjadi pada para relawan saat terjadi bencana alam juga relatif sama. Peningkatan reaksi positif dipresentasikan bukan sekedar peningkatan kesejahteraan umum. Perbedaan pola reaksi juga berhubungan dengan mekanisme koping (coping style) dan usia. Korban dan penyintas yang masih kanak-kanak lebih rentan mengalami trauma, namun juga relatif masih bisa diarahkan untuk mengalihkan perhatian untuk mengurangi trauma. Saat siang hari umumnya bisa dilakukan manipulasi lingkungan dengan cara anak-anak diajak sibuk bermain dan bercerita atau melakukan aktivitas lain yang menyenangkan. Salah seorang anak bahkan menyatakan kepada orang tuanya agar mereka tetap tinggal di pengungsian, tidak perlu kembali ke rumah. Ketika ditanya alasannya, Sang Anak menyatakan karena di pengungsian banyak rekan bermain sehingga lebih menyenangkan baginya.

Informan lain menggambarkan bahwa dirinya tidak bisa hanya diam dan pasrah dengan keadaan. Kehidupan terus berlanjut, dan kebutuhan harus terpenuhi. Beberapa masih bisa berupaya dengan sumber daya yang tersisa, misalnya dengan masak makanan seadanya dan membuat nasi puyung (nasi bungkus porsi kecil dengan lauk sejumput abon dan/atau ayam suwir dan/atau kacang tanah goreng). Makanan tersebut dijual di sekitar lokasi rumah/pengungsian beberapa hari setelah kejadian gempa pertama.

Situasi setelah memasuki pekan ketiga pasca gempa pertama kali bahkan terlihat lebih banyak lagi yang sudah mulai aktivitas yang produktif, misalnya berdagang. Bahkan saat sesi penanganan trauma bagi kanak-kanak, ada seorang pengungsi yang menyaksikan acara sambil tetap berjualan rokok dalam kantong plastik yang dibawanya. Hal ini menunjukkan semangat untuk tidak berdiam diri dan berusaha mulai produktif, namun sayangnya yang dimanfaatkan justru perilaku tidak sehat (merokok) yang memang relatif bertahan

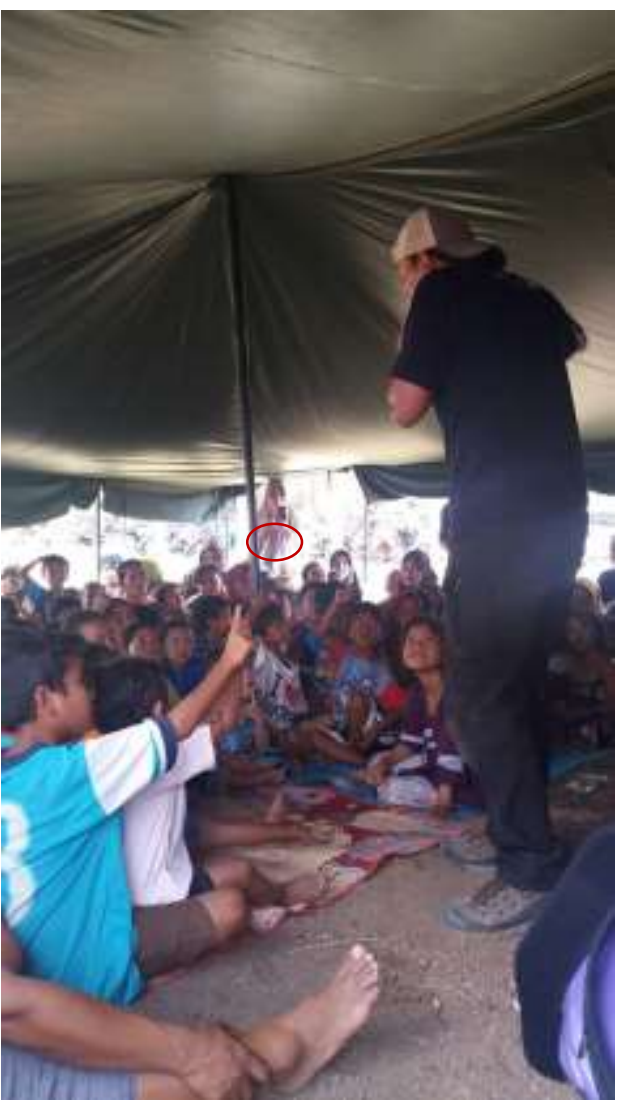
dilakukan baik korban maupun relawan.

Gambar 5. Salah seorang pengungsi menyaksikan sesi bercerita sambil membawa rokok dagangannya 

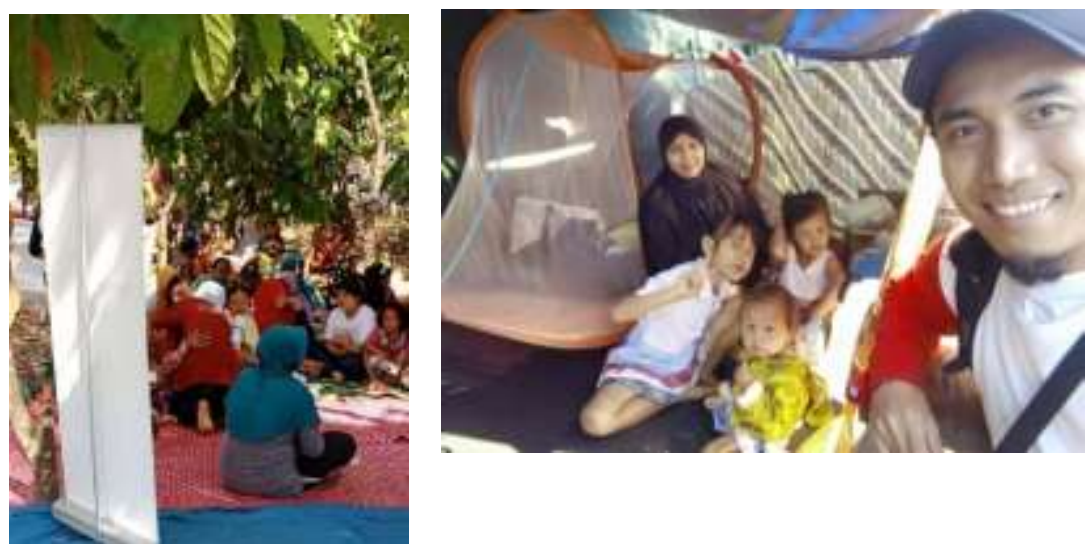

Gambar 6. Suasana Pengungsi saat dikunjungi, pelukan merupakan variabel komunikasi yang dapat merepresentasikan empati

Sumber: Dokumentasi pribadi

Salah satu informan (laki-laki, 60 tahun) yang diwawancara selepas waktu maghrib menyatakan bahwa pemandangan para laki-laki sesama korban duduk mengobrol di sisi jalan di antara tenda pengungsi sangat biasa terlihat bahkan hingga larut malam. Makan dan minum (termasuk kopi) tersedia di dapur umum. Namun untuk rokok tentu tidak disediakan, dan tetap dibeli walaupun harganya lebih mahal dibanding harga pada situasi normal (bisa mencapai hampir 2 kali lipat). Bagi pedagangpun harga yang ditetapkan memang sudah diperhitungkan dengan modal dan kondisi situasional lain, mereka merasa tidak mengambil untung besar.

Umumnya pengungsi memiliki perasaan negatif akibat trauma maupun karakteristik pribadi (personality) dan bisa jadi situasi budaya. Badai Haiyan 2013 yang menghantam Filipina memberikan dampak kepada korban, perasaan yang muncul di antaranya tanpa daya dan ketakutan, bersalah dan malu, serta merasa sendiri. Penduduk yang mampu bertahan (selamat) dari bencana dan juga mengalami perasaan positif dan negative pada saat bersamaan, antara lain merasa kuat dan percaya diri, senasib dan menerima/diterima, serta senang/puas jika bisa menolong orang lain (Nemeth et al., 2012). Perasaan yang sama tentu dirasakan korban gempa Lombok. Ada di antara mereka yang kondisi mentalnya sukup stabil dan positif seperti seorang informan yang ketika ditanya perasaannya dijawab, "Bahagia." Situasi yang sama dilakukan saat terjadi Badai Katrina pada 2005 di Amerika Serikat, peserta diminta untuk menyampaikan perasaannya dalam sesi diskusi kelompok kecil (Nemeth et al., 2012). Perasaan positif juga dapat dibangun dengan menggunakan gambar/foto, kemudian peserta diminta menyampaikan harapannya, hal ini dilakukan pada korban bencana triple di Jepang pada 2011 (Mann et al., 2018).

Jawaban itu dikonfirmasi dengan pertanyaan reflektif, "Ohh.. bahagia ya bu... Kalau boleh tau, apa yang membuat ibu bahagia?" Dijawab, "Karena saya sehat, selamat, keluarga ada, berkumpul di sini.." Pernyataan ini menunjukkan perasaan positif masih ada pada sebagian kecil korban, dan harapannya mereka kemudian bisa melihat potensi yang masih mereka miliki (tidak melulu melihat kekurangan dan kelemahan). Jika sebagian orang positif ini ditemukan kemudian diupayakan untuk mempengaruhi orang di sekitarnya, maka komunitas pada gilirannya dapat diberdayakan. Upaya yang dilakukan berikutnya yaitu menggali permasalahan yang dirasakan dilanjutkan dengan menginventarisasi alternatif penyelesaian masalah.

Penanganan berdasarkan kebutuhan korban dan pemulihan tiga aspek penting dalam korban, yaitu emosional, intelektual, dan spiritual diharapkan mampu memulihkan kondisi korban bencana secara menyeluruh (Nugroho et al., 2013). Diperlukan intervensi sistematis 
untuk mengembangkan masyarakat agar segera bergerak, membangun, dan memberikan kontribusi terbaik bagi upaya pemberdayaan. Kegiatan intervensi sebaiknya tidak dilakukan secara hit and run namun rutin/periodik dalam kurun waktu tertentu untuk menjamin keberhasilan dan dampak positif bagi pemberdayaan masyarakat.

\section{KESIMPULAN DAN SARAN}

Situasi bencana, khususnya gempa (yang umumnya tidak terjadi sekali namun diikuti gempa susulan) mengakibatkan keadaan kacau dan kerusakan. Namun demikian bukan berarti para korban cukup pasrah dan tidak melakukan apa-apa. Keberadaan perasaan positif perlu ditemukan dan dipelihara serta ditularkan kepada orang lain/komunitas agar masyarakat dapat segera bangkit dan melakukan aktivitas yang masih mungkin dilakukan. Perasaan positif mengakibatkan seseorang bisa melihat potensi yang dimilikinya, bukan hanya melihat kelemahan dan masalah, karena sejatinya penyelesaian masalah sedapat mungkin dilakukan dari dan oleh masyarakat sendiri.

Secara nyata kegiatan dapat dilakukan dengan curah pendapat dilanjutkan diskusi tentang situasi yang sedang terjadi. Berikutnya diskusi dilanjutkan dengan alternatif solusi yang dapat dilakukan dengan mempertimbangkan potensi yang masih dimiliki. Akhir diskusi diperlukan pernyataan komitmen agar rencana yang disusun bersama dapat dilaksanakan dengan kontribusi semua pihak sesuai kemampuan masing-masing. Hal ini tidak terbatas dapat dilakukan oleh kelompok orang dewasa, namun dapat juga diterapkan pada kelompok remaja dan anak-anak.

Upaya menemukan dan mengembangkan perasaan positif dapat dilakukan oleh masyarakat/komunitas dengan difasilitasi relawan dan pemerintah. Dibutuhkan sinergi dan koordinasi para fasilitator agar kegiatan yang dilakukan berkesinambungan hingga tujuan tercapai.

\section{UCAPAN TERIMA KASIH}

Kami mengucapkan terima kasih kepada Relawan Indonesia Mandiri, TIGER, DEKAP, dan PYD yang telah memberi kesempatan bergabung dalam tim relawan untuk gempa Lombok, Sulawesi, dan Banten. Secara khusus ucapan terima kasih disampaikan kepada dr. Seno Purnomo, M. Sofyan, Koko, Darto, dan Dean Raharjo yang telah banyak membantu sejak keberangkatan hingga pulang dengan terus memberikan informasi serta dokumen pendukung.

\section{DAFTAR PUSTAKA}

Bandura, A. 2016. Moral Disengagement How People Do harm and Live with Themselves (First prin). Worth Publishers.

BPS Indonesia. 2017. Statistik Lingkungan Hidup Indonesia 2017. Buletin Tataruang BKPRN, 91(1), 186-189. https://doi.org/10.1016/0022-2364(91)90424-R

Karen Glanz, Barbara K. Rimer, K. V. 2017. Health Behavior and Health Education. In Jossey-Bass Inc (Vol. 107, Issue 5). https://doi.org/10.1016/S0033-3506(49)81524-1

Mann, C. L., Gillezeau, C. N., Massazza, A., Lyons, D. J., Tanaka, K., Yonekura, K., Sekine, H., Yanagisawa, R., \& Katz, C. L. 2018. Fukushima Triple Disaster and the Road to Recovery: a Qualitative Exploration of Resilience in Internally Displaced Residents. Psychiatric Quarterly, 89(2), 383-397. https://doi.org/10.1007/s11126-017-9542-7

Moran, C., \& Colless, E. 1995. Positive reactions following emergency and disaster responses. Disaster Prevention and Management: An International Journal, 4(1), 5560. https://doi.org/10.1108/09653569510079050 
Nemeth, D. G., Kuriansky, J., Reeder, K. P., Lewis, A., Marceaux, K., Whittington, T., Olivier, T. W., May, N. E., \& Safier, J. A. 2012. Addressing anniversary reactions of trauma through group process: The Hurricane Katrina anniversary wellness workshops. International Journal of Group Psychotherapy, 62(1), 129-142. https://doi.org/10.1521/ijgp.2012.62.1.129

Nugroho, D. U., R, N. U. P., Rengganis, N. S., \& Wigati, P. A. 2013. Sekolah Petra ( Penanganan Trauma ) Bagi Anak Korban Bencana Alam. Jurnal Ilmiah Mahasiswa, 2(2), 97-101.

Van Bentum, J. S., Sijbrandij, M., Huibers, M. J. H., Huisman, A., Arntz, A., Holmes, E. A., \& Kerkhof, A. J. F. M. 2017. Treatment of intrusive suicidal imagery using eye movements. International Journal of Environmental Research and Public Health, 14(7), 1-15. https://doi.org/10.3390/ijerph14070714

Vázquez, C., Cervellón, P., Pérez-Sales, P., Vidales, D., \& Gaborit, M. 2005. Positive emotions in earthquake survivors in El Salvador (2001). Journal of Anxiety Disorders, 19(3), 313-328. https://doi.org/10.1016/j.janxdis.2004.03.002

World Bank. 2016. Indonesia's Rising Divide. The World bank. 